ICAMS $2016-6^{\text {th }}$ International Conference on Advanced Materials and Systems

\title{
RESEARCH ON THE HYDROLYSIS OF HIDE WASTE IN THE PRESENCE OF NATURAL POLYMERS
}

\author{
GABRIEL ZĂINESCU ${ }^{1}$, ANDREEA HANU ${ }^{2}$, RODICA ROXANA CONSTANTINESCU ${ }^{1}$, \\ DANA CORINA DESELNICU ${ }^{3}$ \\ ${ }^{1}$ INCDTP - Division Leather and Footwear Research Institute (ICPI), 93 Ion Minulescu st., \\ 031215, Bucharest, Romania, email: icpi@icpi.ro \\ ${ }^{2}$ University of Vienna, Faculty of Geosciences, Geography and Astronomy, A-1090 Vienna \\ Althanstraße 14 (UZAII) \\ ${ }^{3}$ University Politehnica Bucharest, 313 Splaiul Independentei, sector 6, Bucharest, Romania, \\ dana.deselnicu@upb.ro
}

\begin{abstract}
Like other industries, the leather processing industry is forced to face high costs for waste treatment and disposal. Consequently, researchers are seeking solutions for effective recovery of organic waste from tanneries through various biochemical treatments in order to obtain protein biofertilizers. The novelty is based primarily on the fact that the starting point of the promoted technologies is the development of new complex products obtained by processing organic waste, called hydrogels with collagen structure, with applications in agriculture. This paper presents an innovative process for the biochemical degradation of pelt waste in order to obtain encapsulated protein biocomposites to be used as fertilizers for poor soils and for plant growth. The proposed method consists in the treatment of raw hide waste by direct hydrolysis of protein waste in an acidic environment, in combination with other polymers (polyacrylamide, starch, urea, acrylic, maleic, cellulose, etc.), thus obtaining hydrogels with collagen structure. For this purpose natural sources of protein are enriched by the addition of macro- and/or micronutrients, resulting in compounded complex systems, namely protein hydrogels. Following experiments it can be concluded that direct hydrolysis of a protein source in the presence of natural or synthetic polymers results in hydrogels with collagen structure to improve soil quality and horticulture.
\end{abstract}

Keywords: protein waste, hydrogel, tannery

\section{INTRODUCTION}

Organic biopolymers are a source of raw materials for agriculture, as protein waste composition provides sufficient elements to improve the composition of degraded soils and plants can harness some micro- or macroelements: nitrogen, phosphorus, calcium, boron, iron, magnesium, sodium, potassium, etc.

Obtaining hydrogels with collagen structure by pelt waste hydrolysis with applications in agriculture is a novelty, given that collagen is used only in medicine.

Compared to hydrogels based on synthetic polymers, hydrogels based on biopolymers have the advantage of biodegradability, biocompatibility and low toxicity (González et al., 1992).

Multicomponent absorbent hydrogel-type networks are next generation materials, with three-dimensional structure and high swelling capacity. The applications of these materials are diversifying, in recent years entering the fields of agriculture, food, pharmaceuticals, electrical devices and electronics, environmental protection and biomaterials (Kopeček, 2007). Hydrogels have a distinct three-dimensional structure and although they have a high water content, hydrogels are water-insoluble due to the crosslinked (physical or chemical) structure of the steric or crystalline linkages. The hydrogel swells when it comes into contact with the aqueous solution (Pooley et al., 2010). 
Hydrogels can be obtained by two major mechanisms: hydrogels with covalent or irreversible links and hydrogels with reversible or physical links. The second category includes various subclasses such as ionic interactions (ionic hydrogels or cross-linked polyelectrolyte complexes) and secondary interactions ("entangled" hydrogels, grafted or complexed hydrogels, etc.) (Hennink et al., 2002).

The area of hydrogel synthesis was broadened by introducing natural polymer or composites of natural and synthetic polymers and continues to boom due to multiple and important applications of hydrogels particularly in medicine and pharmacy, as well as in other areas, such as agriculture.

The applications of hydrogels in agriculture aim at water retention in the soil or controlled release of pesticides or fertilizers (Azeem et al., 2014). In the first case, the application is based on hydrogels' ability to quickly absorb large amounts of water and then release it gradually, supplying plants with water for longer periods after watering the field (rain or irrigation) has ceased.

Hydrogels as controlled fertilizer release systems in agriculture have the major advantage of combining water absorption and its slow release in the interval between rainfalls or irrigations. Therefore they have the ability to retain water in the soil, with the property of slowly releasing fertilizer at the root, and the indisputable advantages presented above. For this reason, encapsulation of fertilizers in hydrogels with high water absorption ability has been researched more intensively in the past years, although there are not many papers published, particularly in the area of biodegradable polymers.

Literature on hydrogels with applications in controlled release of fertilizers (HECF) reveals some observations on the synthesis, structures, fertilizer release method, etc. In terms of the synthesis process HECF have been obtained in solution, in inverse suspension, by dispersing the aqueous solution of monomers into a water-immiscible organic solvent. The method has obvious advantages, as HECF are directly obtained as particles.

Depending on the structure of the resulting fertilizer particle, hydrogel may form the matrix where the fertilizer is embedded or the coating of the solid fertilizer (mono- or multi-layered particles) (Puccini et al., 2015).

Examples of synthesis of hydrogels for agricultural uses include: a hydrogel based on starch, carboxymethyl cellulose (CMC), and cross-linked polyacrylamide, obtained by radical polymerization of acrylamide in aqueous solution in the presence of N,N'methylenebisacrylamide (MBA), crosslinking agent (Abd El-Rehim et al., 2006).

Hydrogels with applications in agriculture were also obtained by analogous polymer reactions. For example, in 2004 (Katima et al., 2004) the reaction between polyvinyl alcohol and phosphoric acid in an aqueous solution was used, followed by neutralization with sodium carbonate. The result was a hydrogel crosslinked by phosphate bridging and with sodium phosphate side groups. The hydrogel had the ability to slowly release phosphate groups in aqueous/wet medium.

Other researchers have obtained starch-sodium alginate hydrogels by mixing aqueous solutions of these polymers, which are composite hydrogels with applications in agriculture. Composite hydrogels have been used both as a matrix, and as a fertilizer particle coating (Gao et al., 2015). 
ICAMS $2016-6^{\text {th }}$ International Conference on Advanced Materials and Systems

\section{EXPERIMENTAL DATA}

Biotechnology for the preparation of protein biocomposites mainly consists of hydrolysis of pelt waste with the enrichment and/or compounding with polymers (corn starch, maleic copolymers, etc.) for use as conditioners and fertilizers (Zăinescu et al., 2014).

The research paper presents exploratory research that starts from obtaining new complex products - polymer multicomponents - called hydrogels, by processing pelt waste for applications in agriculture.

The paper presents the preparation of biodegradable polymer mixtures obtained from hydrolysis and enrichment of resulting hydrolysate with phosphorus and potassium.

In this study, we used limed hide waste from fleshing and trimmimg cattle hides (weight category $35 \mathrm{~kg}$ ) from SC Pielorex Jilava tannery, Ilfov County, Romania. Raw hide contains (based on dry weight) $50-68 \%$ protein, $0.6-9 \%$ fat and $15-50 \%$ ash.

An innovative process has been proposed, namely a direct hydrolysis of pelt waste in an acid medium, combined with other polymers (polyacrylamide, starch, acrylic, maleic, urea, cellulose, etc.) to obtain hydrogels with collagen structure.

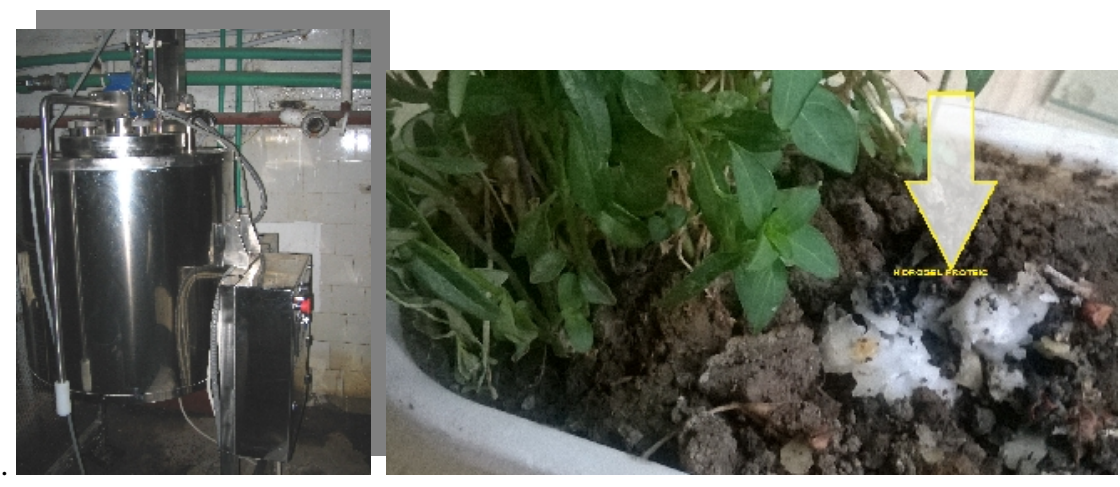

Figure 1. Pilot plant for developing hydrogel with collagen structure

The technological process for obtaining protein hydrogels is presented below:

- an amount of $4.6 \mathrm{~kg}$ of pelt waste is washed with water at $20-25^{\circ} \mathrm{C}$ in a drum for 30-80 minutes and delimed with $2-3.5 \%$ ammonium sulfate for 2-3.5 hours; waste is then ground using a TC 32 grinder (double knives) from SAP company, Italy;

- the mixture is hydrolysed at a temperature of $85-97^{\circ} \mathrm{C}$ for $2.5-3.5$ hours, by adding about 4-6 liters of water in which were dissolved 1.3-2.8\% concentrated sulfuric acid, 8-10\% corn starch and 3-4.5\% dipotassium phosphate $\mathrm{K}_{2} \mathrm{HPO}_{4} \cdot 3 \mathrm{H}_{2} \mathrm{O}$ (to improve the nutritional properties by the addition of phosphorus and potassium required for plant growth and development), all quantities are relative to the mass amount of ground pelt waste;

- a natural polymer based on vegetable oil, labeled "EZ" (3-5 ml per kg of ground pelt) is then added and $2.5-4.5 \%$ urea can be added as plasticizer, continuing to stir in an autoclave at a temperature of $85-95^{\circ} \mathrm{C}$ for $1-1.5$ hours, and then the mixture is removed from the autoclave in plastic drums. 
Collagen-starch-urea hydrogels are thus prepared, which can be extruded into biodegradable films for use in agriculture (Zăinescu et al., 2016).

\section{RESULTS AND DISCUSSIONS}

A hydrogel is defined as a polymer network which has the property of absorbing large amounts of solvent causing macroscopic changes in the polymer. The most important property of hydrogels is their degree of swelling and dissolution and water release of nutrients needed for plant growth.

An attenuated total reflectance spectrophotometer, FT/IR-ATR, Perkin Elmer USA was used to highlight the structural changes in the process of hydrolysis and interaction with various synthetic polymers. Knowing the main spectral characteristics of protein biopolymers in the IR and UV/Vis range, some significant bands for the amide structure were selected.

The IR spectrum shows amide I, II and III bands at about 1660,1550 and $1240 \mathrm{~cm}^{-1}$, respectively.

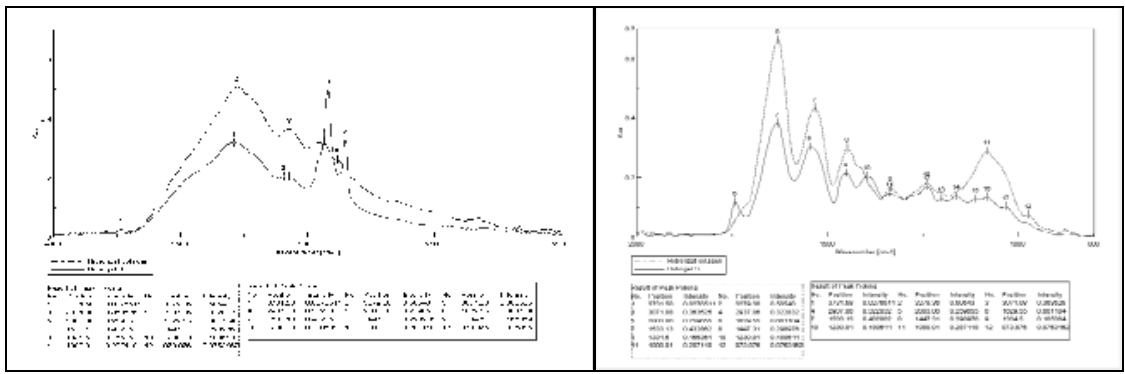

Figure 2. IR spectrum of collagen-starch-urea hydrogel

Hydroxyl groups and the hydrogen bonds are recorded between 3600 and $3100 \mathrm{~cm}^{-1}$. According to the spectral assignments, in the case of collagen hydrolysate bands corresponding to amide groups were observed $\left(\gamma_{\mathrm{C}=0}\right.$ at $1645 \mathrm{~cm}^{-1}, \delta_{\mathrm{NH}}$ and $\gamma_{\mathrm{C}-\mathrm{N}}$ at 1556 $\mathrm{cm}^{-1}$ ). If the band at $1550 \mathrm{~cm}^{-1}$ shifts to $1530 \mathrm{~cm}^{-1}$, the movement is considered a marker of distortion. In the case of collagen hydrolysates, some of the $\mathrm{OH}$ groups are replaced with methoxy groups $\left(\mathrm{CH}_{3}\right)$, attenuating hydrogen bonds, decreasing crystallinity of the collagen and increasing water solubility. Thus, the presence of collagen, urea and starch was confirmed in the molecular structure of the hydrogel.

The protein was encapsulated using a natural product based on vegetable oil labeled "EZ" (Figure 3). 
ICAMS $2016-6^{\text {th }}$ International Conference on Advanced Materials and Systems

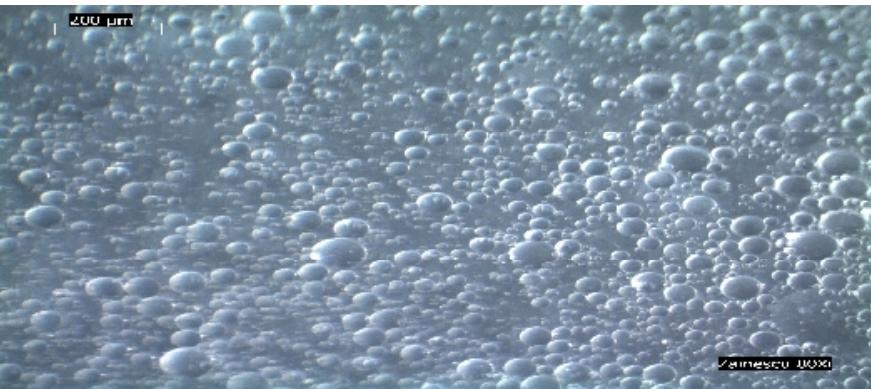

Figure 3. Microscopic image of encapsulated hydrogel with collagen structure (80x)

Physical-chemical analyses of hydrogels obtained in laboratory and pilot stage were carried out in the Quality Control and Testing Laboratory of ICPI (Table 1). The chemical analysis of hydrogel with collagen structure for field experiments indicated the $\mathrm{N}_{13} \mathrm{P}_{9} \mathrm{~K}_{12}$ composition (total nitrogen $13.71 \%$; phosphorus $\mathrm{P}_{2} \mathrm{O}_{5} 3.64 \%$; potassium $\mathrm{K}_{2} \mathrm{O}_{5}$ $6.18 \%)$.

Table 1. Physical-chemical properties of experimental samples

\begin{tabular}{|c|c|c|c|c|c|}
\hline \multirow[t]{2}{*}{ No. } & \multirow[t]{2}{*}{ Characteristics } & \multirow[t]{2}{*}{$\overline{\mathrm{UM}}$} & \multicolumn{2}{|c|}{$\begin{array}{l}\text { Sample code / } \\
\text { Determined values }\end{array}$} & \multirow[t]{2}{*}{ Standard method } \\
\hline & & & $4 \mathrm{~L}$ & $5 \mathrm{P}$ & \\
\hline 1 & Dry substance & $\%$ & 24,60 & 10,72 & SR EN ISO 4684: 2006 \\
\hline 2 & Ash & $\%$ & 7,89 & 6,06 & SR EN ISO $4047: 2002$ \\
\hline 3 & Total nitrogen & $\%$ & 8,17 & 13,71 & SR ISO 5397 : 1996 \\
\hline 4 & Protein substance & $\%$ & 45,92 & 77,05 & SR ISO 5397 : 1996 \\
\hline 5. & $\mathrm{pH}$ & $\mathrm{pH}$ units & 4,53 & 5.53 & STAS 8619/3: 1990 \\
\hline
\end{tabular}

All these hydrogels with collagen structure may be used as smart biofertilizers, particularly as foliar fertilizers.

\section{CONCLUSIONS}

Obtaining hydrogels with collagen structure by hydrolyzing pelt waste for applications in agriculture is a novelty, given that the collagen structure is mainly used in the composition of hydrogels used in medicine. In support of this are the most recent scientific reports in this area related to the interest of researchers in interdisciplinary fields concerning the preparation of hydrogels with collagen structure. This scientific paper is based on a new concept, that of performing direct hydrolysis, using a polymer and nutritional multicomponent system required to obtain hydrogel for agriculture.

Thus experiments in the pilot phase have established the technological process for preparation of encapsulated starch-urea hydrogels with collagen structure starting from pelt waste. Optical microscopy and IR analysis confirmed that the protein source can be transformed by direct hydrolysis of the protein multicomponent system into collagen hydrogels. 
Optimal parameters were set for preparation of encapsulated hydrogel with collagen structure with controlled release of nutrients (nitrogen, phosphorus, potassium, boron, iron, etc.) necessary for plant growth.

\section{Acknowledgements}

This work was financially supported by MENCS -ANCSI, in the frame of Core Program project PN 16340106 project: "Polymer hydrogels with collagen structure for obtaining smart multifunctional products".

\section{REFERENCES}

Abd El-Rehim, H.A., Hegazy, E.-S.A. and Abd El-Mohdy, H.L. (2006), "Effect of various environmental conditions on the swelling property of PAAm/PAAcK superabsorbent hydrogel prepared by ionizing radiation", Journal of Applied Polymer Science, 101, 3955-3962.

Azeem, B., KuShaari, K.Z., Man, Z.B., Basit, A. and Thanh, T.H. (2014), "Review on materials and methods to produce controlled release coated urea fertilizer", Journal of Controlled Release, 181, 11-21.

Gao, X., Li, C., Zhang, M., Wang, R. and Vhen, B. (2015), "Controlled release urea improved the nitrogen use efficiency, yield and quality of potato (Solanum tuberosum L.) on silt loamy soil", Field Crops Research, 81, 60-68.

González, N., Vadillo, I., Trigo, R. and Teijon, J. (1992), "Hydrogeles: Síntesis, propiedades y aplicaciones", Rev. Ibe. Pol., 1(1), 79-83.

Hennink, W.E. and van Nostrum, C.F. (2002), "Novel crosslinking methods to design hydrogels", Advanced Drug Delivery Reviews, 54, 13-36.

Katime, I., Katime, O. and Katime, D. (2004), Los materiales inteligentes de este milenio: Los hidrogeles macromoleculares. Síntesis, propiedades y aplicaciones, Servicio Editorial de la Universidad del País Vasco, Bilbao, España.

Kopeček, J. (2007), “Hydrogel biomaterials: A smart future”, Biomaterials, 28, 5185-5192.

Pérez-Limiñana, M.A., Escoto-Palacios, M.J., Martínez-Sánchez, M.A., Ferrer-Palacios, J., Arán-Aís, F. and Orgilés-Barceló, C. (2014), "Recovery of Tannery Wastes for Functional Microencapsulated Products", Proceedings of The 5th International Conference on Advanced Materials and Systems - ICAMS 2014, Bucharest, 479.

Pooley, S.A., Rivas, B.L., Lillo, F.E., Pizarro, G. and Del, C. (2010), "Hydrogels from acrylic acid with N,Ndimethylacrylamide: synthesis, characterization, and water absorption properties", Journal of the Chilean Chemical Society, 55, 19-24.

Puccini, M., Seggiani, M., Vitolo, S. and Lucio, L. (2015), "Utilization of starch films plasticized with urea as fertilizer for improvement of plant growth”, Chemical Engineering Transactions, 43, 7005-7010.

Zăinescu, G., Albu, L., Deselnicu, D., Constantinescu, R.R., Vasilescu, A.M., Nichita, P. and Sîrbu, C.A. (2014), New Concept of Complex Valorization of Leather Wastes, Materiale plastice, 51(1), 90-93.

Zăinescu, G., Coară, Gh., Florescu, S.M., Constantinescu, R.R. (2016), "Obtaining polymer hydrogels with collagenic structure from pelt waste", The SGEM Albena-Bulgaria Conference Proceedings, Book 4 Energy and Clean Tehnologies, Vol II, 73- 81. 